\title{
Exploring tablet PC lectures: Lecturer experiences and student perceptions in biomedicine
}

\author{
Julia Choate, George Kotsanas, Phillip Dawson \\ Monash University, Australia
}

\begin{abstract}
Lecturers using tablet PCs with specialised pens can utilise real-time changes in lecture delivery via digital inking. We investigated student perceptions and lecturer experiences of tablet PC lectures in large-enrolment biomedicine subjects. Lecturers used PowerPoint or Classroom Presenter software for lecture preparation and in-lecture pen-based inking. Using surveys and lecturer interviews, students and lecturers were asked to reflect on their tablet PC lectures in comparison to non-tablet lectures that used prepared images and a laser pointer. Quantitative survey responses suggested that students felt that the tablet lectures were more interesting, that they were more capable of keeping up with the lecturer, and they enhanced their understanding of the lecture content. Qualitative analysis of written comments indicated that students appreciated the real-time writing and drawings, particularly because these were visible on lecture recordings. When reflecting on their nontablet lectures, most lecturers used the pen-based writing, drawing and highlighting tablet functions and reduced lecture pace and content for their tablet lectures. Long-term tablet use led to lecturers making more use of digital inking, with less use of prepared images. Our results support the idea that tablet PC-supported lectures are conducive to improved management of cognitive load via reduced lecture pace and content.
\end{abstract}

\section{Introduction}

This paper reports on student perceptions and lecturer experiences of using tablet PCs to deliver lectures in an undergraduate biomedical science course with a large student cohort. The tablet PCs used in this study were laptops (rather than a slate model) with a touch-sensitive screen that allowed handwriting input with a specialised digital pen (digital inkboard). The tablet PC's display was synchronised with a projector screen. In a traditional undergraduate biomedical lecture, the lecturer digitally projects prepared and pre-scripted images onto a wall behind the lectern and uses a laser pointer to highlight important aspects on the projected images. Importantly, when using the laser pointer, the lecturer most likely will be speaking to the images, with their back to the students. The use of prepared images that cannot be easily altered in real-time may lead to fast-paced lectures packed with content. Students attending these lectures, particularly those for whom English is not their first language, may struggle to take written notes and absorb the content as it is presented. If lecture printouts of the images are made available it may encourage passive student behaviour, where students do not take notes during lectures (Clark, 2008). We argue that lecturer use of digital inking on a tablet PC is effective for large class lectures; the lecturer can face the class and their active real-time digital writing and drawing (that might involve problem solving, for example) can enhance the variety of the lecture delivery and encourage real-time content changes, especially in response to student feedback (Tintarev \& Rydén, 2010). These factors may also lead to a reduction in lecture pace and content, encourage active student participation (particularly via note-taking) and enhance student interest and understanding of their lectures.

\section{Tablet PCs for lecturing}

Educational tablet computing, ranging from iPad-style devices to fully-fledged tablet PCs, is the subject of increasing investment and technological excitement. Tablet PCs allow the user to communicate with the device and their student audience using familiar pen-like gestures. Although much has been written about the pedagogical benefits of this new class of tools (Derting \& Cox, 2008; Lumkes, 2010; Yoon \& Sneddon, 2011; Tintarev \& Ryden, 2010), there is little information about actual classroom uses of the tool in practice (Tintarev \& Ryden, 2010). This is not unusual in educational technology research, which tends to focus more on the "state of the art" than the "state of the actual" (Selwyn, 2010). In this paper we report on the "state of the actual" for the use of tablet PCs to deliver lectures in large-enrolment biomedical sciences subjects at a research-intensive Australian university. 
In terms of technological affordances, the tablet PC is a new class of tools, combining a traditional laptop with a touch-sensitive screen and a specialised pen. In addition to incorporating the laptop's affordances, the tablet PC provides other, somewhat unique features, notably pen-based digital inking and highlighting in multiple colours. Applications of these features include handwritten notes, drawings and annotations. Tintarev \& Rydén (2010) used the term "digital inkboard" to describe a laptop that has digital inking capabilities. In our paper we are particularly interested in the use of tablet PCs by lecturers to support lectures and to enhance the flexibility of lecture delivery, in that the lecturer can use static images, realtime diagrams and writing and can also make real-time changes in the lecture delivery and content (Tintarev \& Rydén, 2010). Tintarev and Ryden (2010) summarised the main differences between the oldstyle writing on transparencies and digital inking on a tablet PC as: lecturers can duplicate presentation pages/slides; digital inking can be more easily erased and/or edited; digital annotations can be saved for distribution to students. Thus, tablet PCs provide most of the affordances of interactive whiteboards (Dawson, 2010), with the notable exception of the gross gestures made possible by the whiteboard's size. Furthermore, the tablet PC enables lecturers to annotate while facing the class whereas non-tablet PC lectures with a laser pointer or large digital whiteboards favour lecturers pointing or writing with their back to the class (Tintarev \& Rydén, 2010).

Tablet PCs have been used in higher education lectures across a variety of disciplines, including: biochemistry (Cox, 2011), chemistry (Derting \& Cox, 2008; Johnson, 2008), engineering (Grainger, Kestell, \& Willis, 2011; Lim, 2011), mathematics (Loch, Galligan, Hobohm, \& McDonald, 2011; Tintarev \& Rydén, 2010; Yoon \& Sneddon, 2011), computer science (Mock, 2004) and statistics (Yoon \& Sneddon 2011 for review). They are generally used in a "one-tablet model of instruction" where only the lecturer uses a tablet PC to project content on the display for student viewing (Derting \& Cox, 2008). In some cases, both instructor and students use tablets; for example, students may use tablets in group exercises during the lecture (Derting \& Cox, 2008; Kam et al., 2005), which may be cost prohibitive in a large class. In this paper, we will focus on the one-tablet model.

Tablet PCs commonly augment the traditional large lecture by providing live digital inking to supplement or replace static presentation of images. Used in this way, tablet PC technology in lectures can create a more interactive and adaptive classroom, relative to the rigidity of static prepared images with a laser pointer (Lumkes, 2010). Interactive is a potentially contentious word here, as it can have many meanings; we prefer the terms pedagogical interactivity (for teacher-student and student-student interaction) and technological interactivity (for interaction between students/teachers and technology) as proposed by Higgins et al. in the interactive whiteboard literature (Higgins, Beauchamp \& Miller, 2007). These are separate concepts and although not mutually exclusive, Higgins et al. found that with interactive whiteboards, greater use of technological interactivity led to lesser pedagogical interactivity.

Since this study did not specifically examine technical or pedagogical interactivity, we propose that the tablet PC lectures encourage active participation of students during the lecture via note-taking and drawing during the lecture, and via the lecturers' real-time digital inking in response to in-lecture student questions. Student note-taking during the lectures may also help to focus their attention (Weitz, Wachsmuth \& Mirliss, 2006). As annotations (and associated spoken cues) may act as signals of particularly relevant content, this note-taking may result in improved learning because the students may be mentally processing the information as they take notes (Kiewa, 1985; Peverley, Ramaswamy, Brown, Sumowksi, Alidoost \& Garner., 2007; Titsworth \& Kiewra, 2004).

In some cases, tablet PC lecturers provide students with annotated notes as a PDF. For example, Cox (2011) used a tablet PC to generate large scale ( 40 x 40 inches) PowerPoint slides with digitally written metabolic maps that were converted to a PDF and distributed to biochemistry students post-lecture. In the last couple of years digital video recording technology has been used to capture real-time digital annotations with the tablet PC (Yoon \& Sneddon, 2011). In this context, the tablet PC has a distinct advantage over prepared presentation images with a laser pointer because the student can view the tablet PC annotations on the digital video. However, laser pointers cannot be viewed on digital videos. The annotations and drawings on the video can aid student revision of the lecture material, especially if they are also posted as a printable file post-lecture (Lumkes, 2010; Yoon \& Sneddon, 2011). 


\section{Tablet PC lectures and student cognition}

In the traditional lecture environment, the teacher can "signal" important information in a variety of ways, including: varying vocal intonation; changing pace; using statements to emphasise important information (for example, "it should be noted that...") and gestures. Tablet PC lecturers do not need to turn their back to the students (as they may do when pointing with a laser pointer at projected slides) and thus the tablet annotations can be associated with visual facial cues from the lecturer (Tintarev \& Rydén, 2010). Each of these types of signaling have been tested in randomized control trials by Cognitive Load Theory (CLT) researchers and have been found to improve learning through a reduction in extraneous cognitive load (Clark, Nguyen \& Swelle, 2006). When lecturers use tablet PCs rather than a traditional laptop or desktop computers for presenting slides, they have access to additional signaling tools not usually present in the lecture space.

In computer-supported learning environments, signals in the form of highlighting, arrows, circling, or other graphical means have been shown to support learning (Felder \& Silverman, 1988). The tablet PC allows the lecturer to use familiar pen gestures to perform this signaling in real-time. Although this may have been possible using a computer mouse, it is not a universal feature of non-tablet delivery. We argue that the use of signaling during tablet PC lecture delivery will lead to lectures that are easier for students to follow and comprehend than traditionally prepared static image presentations.

In addition to supporting the signaling principle of CLT, we argue that tablet PCs may also support the increased drawing of ad-hoc graphics, which may be supported by the modality principle; that is, when the same material is presented both verbally and graphically, verbal information should be in a narrated auditory format, and not as written visual text (Ginns, 2005). Evidence from randomized controlled trials and meta-analysis support the use of graphics and audio to present information that may have a visual component (Carlson, Chandler \& Sweller, 2003). If tablet PCs support lecturers to produce graphical explanations of their material in real-time as they are needed, this may result in improved learning through the modality principle.

There is some evidence that tablet PC lectures can enhance student learning, as determined by improved test results; Derting and Cox (2008) compared undergraduate chemistry students' results in semester one (lecturer used PowerPoint slides and chalkboard) and semester two (lecturer used a tablet PC) and found that the students with the tablet PC lectures performed better in an exam. Student survey responses also suggested that tablet PC lectures helped them understand lecture content. Tilbrook (2010) investigated student performance in an undergraduate science subject that used non-tablet PowerPoint lectures with a laser pointer (2009) and then tablet PC lectures in the following year (2010); student performance (for the same assessment questions and the same lecturer) was significantly improved following the tablet PC lectures. This study was limited by comparisons between two different student cohorts (although statistical analyses were used to normalise the data).

\section{Student engagement with tablet PC lectures}

Student engagement is a contested term (Baron \& Corbin, 2012). Here we define undergraduate student engagement with their lectures as active involvement with and participation during the lecture, especially via note-taking (for a review, see Trowler, 2010). This engagement involves behaviour (the student attends and enthusiastically participates), emotions (student interest and enjoyment during the lecture, a sense of belonging to the lecture group), and cognition (student investment in their learning) (Trowler, 2010). Student engagement in active learning could involve them reading, writing or solving problems; it should also aim to incorporate higher order skills such as creation, analysis and evaluation (Jakee, 2011; Krathwohl, 2002).

Clark (2008) describes the use of non-tablet PowerPoint lectures as a delivery system for providing students with packaged information presented in a beautiful format, with more focus on the presentation than the content. This means the lecture is more about the content than the person communicating the information, i.e., "form without substance will not engage a class" (Clark, 2008, p. 43). Clark argues that PowerPoint can be an effective lecturing tool, maintaining student interest and engagement, if there is variety in the lecture design and presentation (including using compatible technologies such as a tablet PC to add written text) and if students are encouraged to actively participate in the lecture. 
We anticipated that students would be more involved with and attentive during their tablet PC lectures due to the increased note-taking. The tablet PC lectures promote more flexible content delivery and should encourage students to write and solve problems at the same time as the lecturer. These lectures are also likely to be at a slower pace, encouraging student note-taking and lecture comprehension. Previous tablet PC studies support these ideas; Van Oosteveen and Muirhead (2007) in their qualitative survey and one-on-one interviews of 42 Engineering, Science and Applied Science tablet PC lecturers found they felt that the tablets "facilitate greater student-faculty exchanges in class" (p. 6 of 9). This included active student involvement because annotated solutions to problems were worked through at a realistic pace and in a sequential manner. Student evaluations of first year chemistry tablet PC lectures found that they perceived the tablet lectures to enhance "teaching effectiveness", to "create a better learning environment", that they "promoted student learning" and improved the instructor "interaction with students in the class" (Derting \& Cox, 2008). In another study, three different modes of lecture delivery were compared for undergraduate engineering students: PowerPoint slides and pre- and post-lecture handouts; traditional chalkboard (no handouts); and skeleton PowerPoint slides and pre-lecture handouts. Both PowerPoint lecture modes used a tablet PC, but the third mode of delivery made more use of the annotations (Lumkes, 2010). The majority of the students agreed that "It was easy to remain engaged in..." the chalkboard and skeleton PowerPoint (tablet PC) lectures, and the skeleton PowerPoint (tablet PC) lectures "enhanced [their] ability to learn" (Lumkes, 2010, p.357.

Previous studies of student experiences of tablet PCs for teaching have indicated that students appreciate the different colours for highlighting, the use of multimedia, and the ability to digitally save lecture annotations for post-lecture viewing as a video or a static printable file (Lumkes 2010; Yoon \& Sneddon, 2011). In a review of the research literature, Yoon and Sneddon (2011) report that students commonly use recorded tablet PC lectures to catch up on missed lectures (or to replace the live lecture), to replay the lecture to aid in the understanding of the lectures and for revision for exams and tests. They also report anecdotal evidence that these recordings are used to slow down the pace of the lecture, especially by students with English as their second language.

\section{Lecturer experiences of tablet PC lecturing}

Most studies of tablet PC lecturing have focused on student experiences. However, some studies have specifically documented lecturer experiences of tablet lecturing. Weitz et al. (2006), in a survey of 45 lecturers from across their whole institution, found that lecturers commonly drew "diagrams, charts and/or graphs" (42\%), "used the handwriting functionality to draw or write over prepared content" (36\%) and used the tablet whiteboard, i.e., using a blank screen with no prepared content (23\%). In a qualitative analysis of lecturer perceptions of their tablet lectures, Van Oosteveen \& Muirhead (2007) discovered four main themes: (1) "enhancing mobility of faculty" (meaning mobility of faculty across different campuses, and also the mobility of the small, lightweight tablet which encouraged alternative tablet use such as note-taking during academic meetings); (2) "transforming the development of learning materials in and out of class" (i.e., half of lecturers prepared pre-lecture 'handwritten' notes with the tablet; lecturers also prepared slides with overlaid graphics that could be annotated during the lecture); (3) "enhancing faculty feedback to students" (particularly written comments on student assignments); and (4) "altering instructional pacing during lectures" (i.e., slowing lecture pace).

Anderson, Anderson, McDowell \& Simon (2005) developed tablet PC presentation software, called Classroom Presenter, which supports digital inking. They summarised common tablet digital inking by lecturers to include: "attentional marks for emphasizing slide content"; "short written phrases for emphasis"; "spontaneous written examples"; "diagrams used for explanation"; "annotation of diagrams on slides"; and "planned activities such as writing lists or filling in tables". They argued that for the digital inking to be effective and comprehensible it must be easy to read (and this can be affected by the size of the tablet), inking colours should be carefully chosen and clutter should be avoided. This means that lecturers need to carefully plan their slides (e.g. leaving enough blank space for writing). It also suggests that adequate training and practise are essential for effective tablet lectures.

A common experience with tablet PC lectures is technical problems. Lim's (2011) study of 28 engineering academics lecturing with a tablet $\mathrm{PC}$ found that $50 \%$ experienced technical problems with the software and hardware. Weitz et al. (2006) evaluated tablet PC teaching in a pilot project involving 45 
lecturers (across all faculties). They received 38 negative comments about technical issues that included: the system freezing; an oversensitive cursor; the external DVD drive did not work; screen orientation; and problems with the wireless networking. In all of these studies the lecturers were complete novices with tablet PC teaching. In contrast, a small sample of two engineering lecturers who had used tablet-based annotations during lectures reported good responses for both "ease of use" and "ease of integration", with existing technologies in the lecture theatre (Grainger et al., 2011).

\section{Context}

Motivated by the potential of tablet PC technologies to improve student involvement and understanding of their lectures, a team of educational technologists and lecturers investigated the impact of this technology in the large lecture environment. This paper documents a study of tablet PCs in the context of a three-year undergraduate degree, the Bachelor of Biomedical Science (BMS). Annual student enrolments in this course are in excess of 200. Staffing and financial constraints mean that the primary mode of teaching for students enrolled in this course is the one-hour lecture. Within the School of Biomedical Sciences and more broadly across the University there is concern about the apparent decrease in student engagement with their courses. This concern stems from reduced student attendance at lectures, a perceived lack of student participation during lectures, and a split student attention with the nonscholarly uses of mobile devices.

In 2010, a tablet PC lecturing program was initiated in the School of Biomedical Sciences. Pre-lecture training with the tablet PC was offered by pedagogical and technical staff with tablet PC expertise and inlecture technical support was provided for all lecturers. The aims of the program were that lecturers would use the real-time digital inking tablet PC functions and they would have greater flexibility in how they conducted lectures. This style of lecture delivery could encourage active student involvement during the lecture and have a positive outcome on student understanding.

\section{Rationale of the study}

This project used quantitative and qualitative data analysis to investigate student perceptions and lecturer experiences of tablet PC lectures in two subjects (Physiology and Bioinformatics) taught in a Bachelor of Biomedical Science (BMS) degree. The aims of the study were to determine:

(1) Student perceptions of interest, lecture pace and understanding of tablet PC lectures.

(2) Staff perceptions of lecture delivery and content for their tablet PC lectures.

\section{Methodology}

\section{Participants}

In 2010, all lecturing staff in the second year of the BMS degree were invited via staff e-mail and school on-line newsletters to use a tablet PC for lecturing (6 core subjects with 25 lecturers; the subjects were Physiology, Bioinformatics, Anatomy, Biochemistry, Microbiology and Genetics). Academics were asked to express interest via email, and they were then supplied with a tablet PC for use in lectures. Tablets were provided on a first-come, first-served basis. Ten of the twenty-five 2nd year BMS lecturers used a tablet PC for lecturing in 2010. Two of the BMS subjects were involved in the student perceptions of tablet PC lectures: (1) a Physiology subject delivered in the first academic semester of 2010 which had 227 enrolled students and (2) a Bioinformatics subject delivered during the second academic semester which had 215 enrolled students.

\section{Research design}

Students enrolled in Physiology attend three lectures per week, while students enrolled in Bioinformatics attend two lectures per week, during the standard twelve-week semester. In the Physiology subject all of the lecturers (i.e., four) used the tablet PC, whereas in Bioinformatics only one of four lecturers used the tablet PC (this tablet lecturer presented 13 of the 22 Bioinformatics lectures). Lecturers were provided with a Dell Latitude XT2 tablet PC with Classroom Presenter and PowerPoint software installed. Classroom Presenter software is for tablet PC presentations and enables digital inking on exported PowerPoint slides or on a blank "whiteboard". It was developed at the University of Washington 
(Anderson et al., 2005). Prior to the start of each semester, lecturers were provided with training in the use of the tablet PC. This involved demonstrations on how to export PowerPoint slides into Classroom Presenter, inking in PowerPoint and Classroom Presenter, the use of the whiteboard in Classroom Presenter and how to set up the tablet PC in the lecture theatre. Lecturers were also provided with an opportunity to present a practise tablet PC lecture in front of their fellow tablet PC lecturers. In the case of any technical issues, a technician was present during the tablet lectures. The Physiology and Bioinformatics lectures were recorded with the University's Echo360 lecture capture system, which simultaneously records the output from the tablet PC (lecture slides and annotations) together with audio.

Quantitative and qualitative feedback from students and lecturers about their experiences of the tablet PC lectures was obtained through anonymous paper-based surveys (see Table 1). Both surveys were voluntary and were administered by staff independent from this research study. The research was approved by the University Committee for Human Experimentation.

Students were invited to complete the survey during the final lecture for the subject. Administration of the survey was preceded by an oral summary of the tablet PC study (i.e. that tablet PCs with a touch sensitive screen and specialised digital pen were being used by lecturers in their subject). The students were asked to respond to the survey statements by comparing the tablet PC lectures to non-tablet PowerPoint lectures given by lecturers in their subject or other BMS subjects in the same semester.

Lecturers were invited via a written letter at the end of the academic year (i.e., December 2010). In this survey, the lecturers were specifically asked to reflect on how their tablet PC lectures in 2010 were different to the equivalent non-tablet lectures they had given in 2009, using PowerPoint with a laser pointer. The surveys utilised questions and statements that requested written comments or tick the box responses, sometimes on a five point Likert scale, ranging from 1 (strongly disagree) to 5 (strongly agree). Written responses were analysed using a general inductive approach for analysing qualitative evaluation data (Thomas, 2006); the students' written responses were read several times (independently) by the authors (JC \& GK) and broad themes were agreed upon.

Follow up interviews were carried out with three of the lecturers in 2013. This allowed for a long-term evaluation of how the use of tablet PCs had altered their lectures, and also enabled clarification of main themes that emerged from the initial (2010) lecturer survey.

Table 1

Summary of research design

\begin{tabular}{|c|c|c|}
\hline Instrument & Participants & Purpose \\
\hline $\begin{array}{l}\text { Student survey (based on a } \\
\text { student attitudinal survey } \\
\text { published by Derting \& Cox, } \\
\text { 2008) }\end{array}$ & $\begin{array}{l}177 \text { undergraduate biomedical } \\
\text { science students enrolled in the } \\
\text { Physiology and Bioinformatics } \\
\text { subjects }\end{array}$ & $\begin{array}{l}\text { To investigate student } \\
\text { perceptions of the tablet PC } \\
\text { lectures, in particular, the } \\
\text { lecture pace and the student } \\
\text { interest, engagement and } \\
\text { understanding of the lectures. }\end{array}$ \\
\hline $\begin{array}{l}\text { Lecturer survey (developed } \\
\text { from themes emerging from } \\
\text { student feedback) }\end{array}$ & $\begin{array}{l}7 \text { biomedical science lecturers } \\
\text { who lectured the biomedical } \\
\text { science students in their core } 2 \text { nd } \\
\text { year subjects (Physiology, } \\
\text { Bioinformatics, Anatomy, } \\
\text { Biochemistry, Microbiology and } \\
\text { Genetics) }\end{array}$ & $\begin{array}{l}\text { To investigate how using a } \\
\text { tablet PC with a digital pen } \\
\text { altered their traditional } \\
\text { PowerPoint lectures (that used a } \\
\text { laser pointer). }\end{array}$ \\
\hline Lecturer interviews & $\begin{array}{l}3 \text { biomedical science lecturers } \\
\text { who lectured the biomedical } \\
\text { science students in their core } 2 \text { nd } \\
\text { year subjects (Physiology, } \\
\text { Bioinformatics, Anatomy, } \\
\text { Biochemistry, Microbiology and } \\
\text { Genetics) }\end{array}$ & $\begin{array}{l}\text { To investigate how using a } \\
\text { tablet PC with a digital pen } \\
\text { altered their traditional } \\
\text { PowerPoint lectures (that used a } \\
\text { laser pointer). }\end{array}$ \\
\hline
\end{tabular}




\section{Results}

\section{Student perceptions of their tablet PC lectures}

For the Physiology subject, the survey was completed by 104 students ( $46 \%$ of enrolled students) while for Bioinformatics it was completed by 73 students (34\% of enrolled students). Student responses to the statement, "When the lecturer used a tablet PC in class it helped me to keep up with the pace of the lecture", are shown in Figure 1. For Physiology, 83\% of students responded positively (with agree or strongly agree), $7 \%$ negatively (with disagree or strongly disagree) and $10 \%$ were neutral. For Bioinformatics, $75 \%$ of students responded positively, $11 \%$ negatively and $14 \%$ were neutral.

Figure 2 shows student responses to the statement, "When the lecturer used a tablet PC in class it made the lecture more interesting and engaging". For Physiology, $87 \%$ of students responded positively to this statement while $9 \%$ responded negatively and $4 \%$ were neutral. A similar trend was observed in Bioinformatics, where $67 \%$ of responses were positive, $9 \%$ were negative and $23 \%$ were neutral.

Physiology students also responded positively to the statement, "When the lecturer used a tablet PC in class it improved my understanding of the lecture content". From the sample of Physiology students, 80\% responded positively, 12\% negatively and $8 \%$ were neutral (see Figure 3). For Bioinformatics the corresponding values were $66 \%$ positive, $12 \%$ negative and $10 \%$ neutral.

Students were asked to respond in writing to the statement, "Briefly comment on the best aspects of the tablet PC lectures". The responses were categorised into seven main themes (see Table 2). The two most common themes were: (1) writing, diagrams or drawing on the lecture slides and (2) annotations on the digital video recording (Echo) of the lecture.

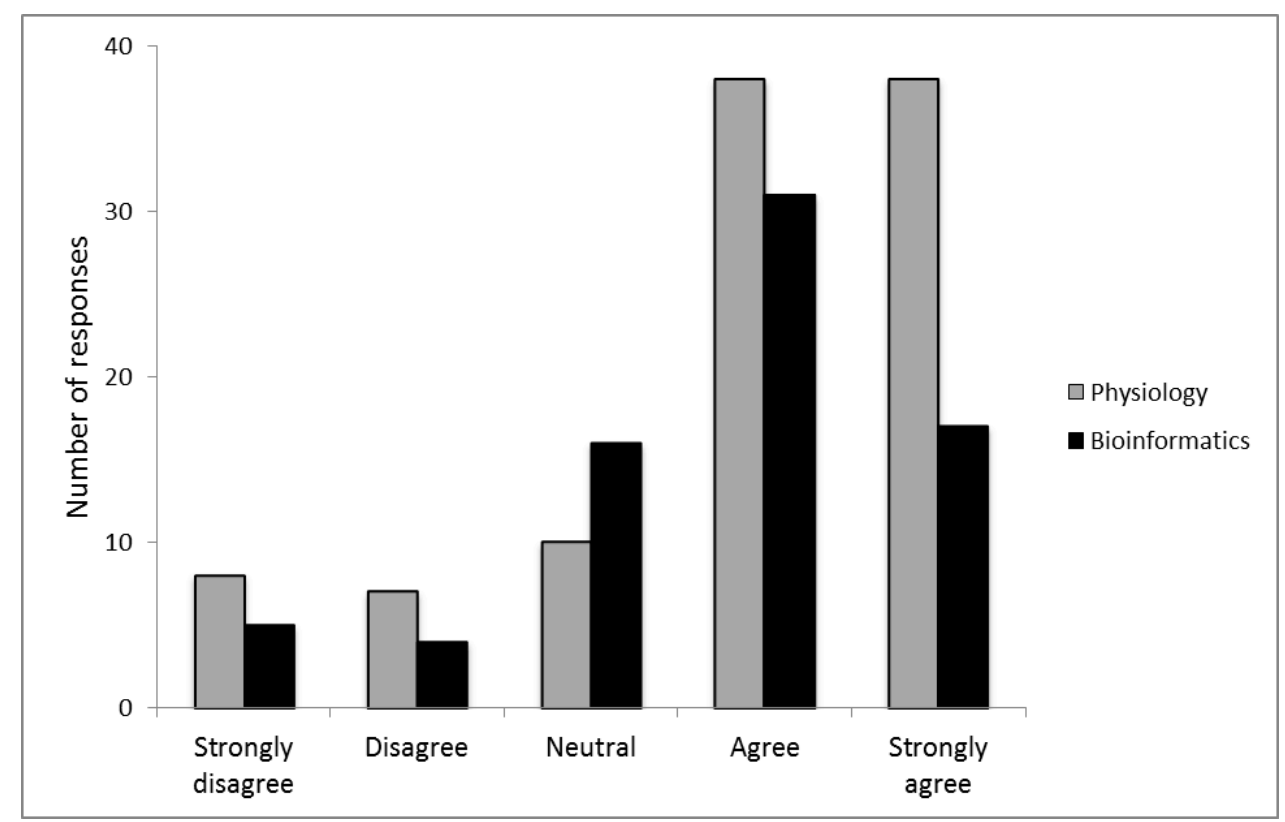

Figure 1. Student responses to the statement, "When the lecturer used a tablet PC in class it helped me to keep up with the pace of the lecture", for two biomedical subjects 


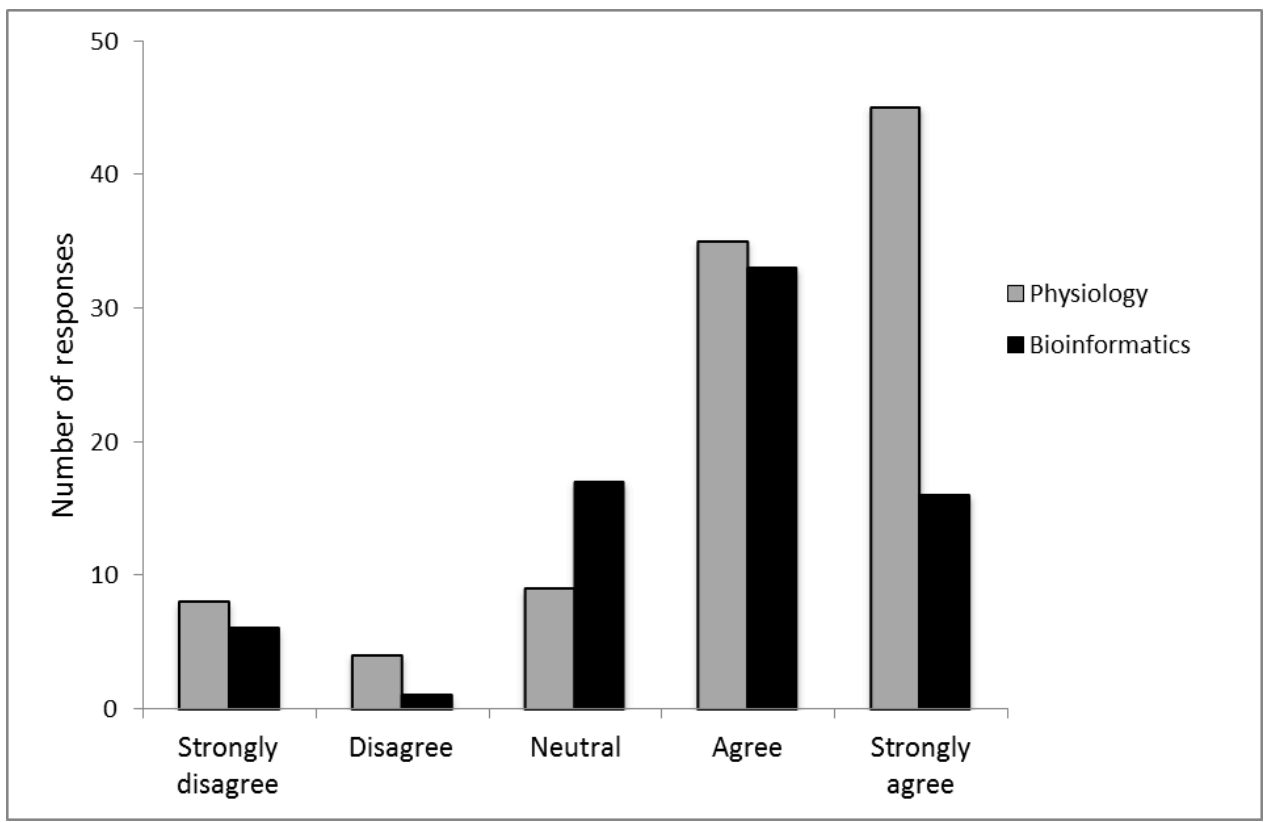

Figure 2. Student responses to the statement, "When the lecturer used a tablet PC in class it made the lecture more interesting and engaging", for two biomedical subjects

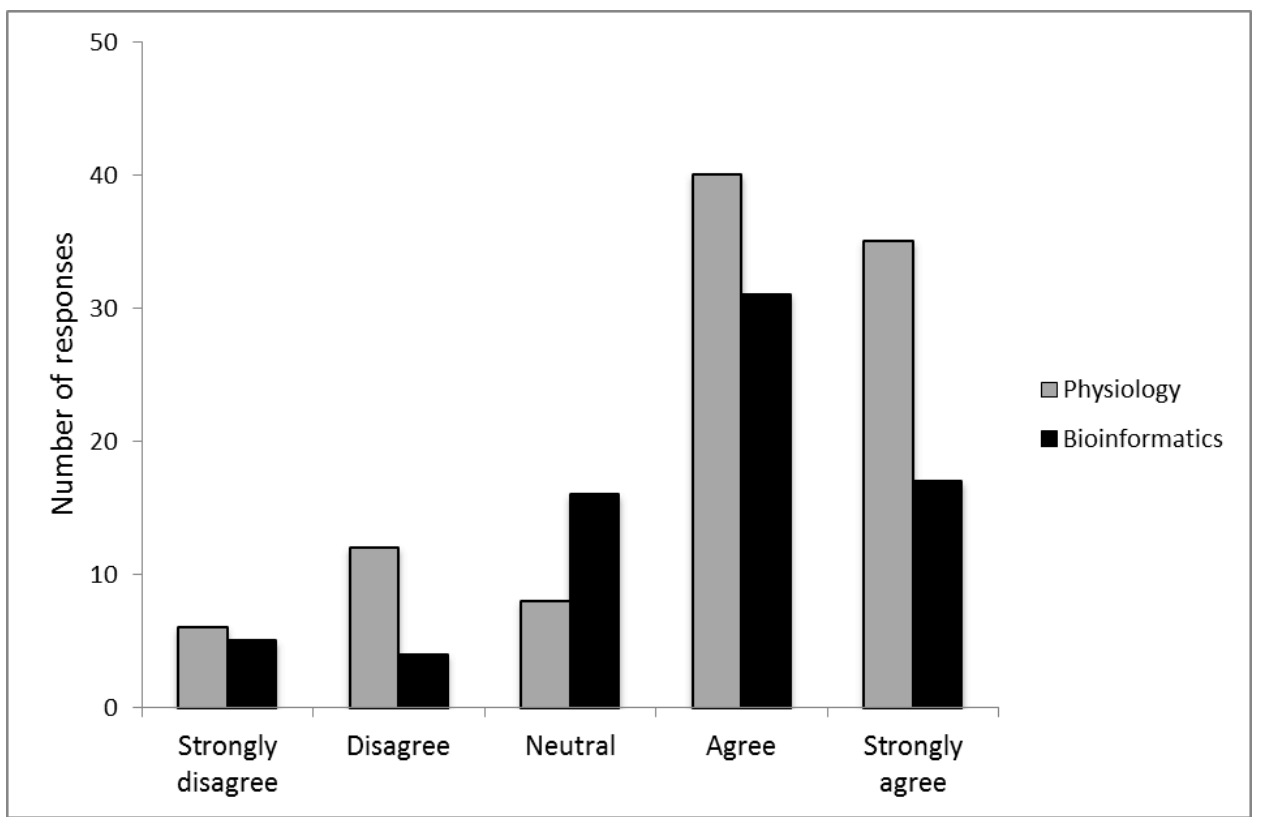

Figure 3. Student responses to the statement, "When the lecturer used a tablet PC in class it improved my understanding of the lecture content", for two biomedical subjects 
Table 2

Main themes of the student responses to the statement "Briefly comment on the best aspects of the tablet $P C$ lectures" for two biomedical subjects

\begin{tabular}{lcc}
\hline $\begin{array}{l}\text { Main themes of the student responses to, } \\
\text { "Briefly comment on the best aspects of } \\
\text { the tablet PC lectures" }\end{array}$ & $\begin{array}{c}\text { Physiology } \\
\text { (number of comments) }\end{array}$ & $\begin{array}{c}\text { Bioinformatics } \\
\text { (number of comments) }\end{array}$ \\
\hline (1) Writing, diagrams or drawing on \\
lecture slides. \\
(2) Annotations on the digital video \\
recording (Echo) of the lecture. \\
(3) Slower pace of lecturer. \\
(4) More interactive and/or engaging. \\
(5) Improved my understanding of \\
content.
\end{tabular}

Note: Total number of comments: Physiology, $n=62$; Bioinformatics $n=49$.

Two examples of tablet PC lecture annotations are illustrated in Figure 4. Fifty students (28\%) thought the digital writing, diagrams or drawing were the best aspects of the tablet PC lectures (Theme 1). Ten $(6 \%)$ of students commented that the slower pace of the lectures made it easier to keep up (Theme 3). Students also commented that the tablet PC lectures were interesting, kept them attentive, and improved understanding of the lecture content (Themes 4-7). Typical student comments addressing the different themes are shown below:

Lecturers were able to write out the key points and illustrate their information in diagrams which made the information more interesting and kept you focused. (Theme 1)

The lecturers being able to write their own notes and diagrams to better illustrate their important points - Makes the lectures easier to keep up with. (Themes 1 and 3)

It kept students' attention and motivated me to attend lectures as the lecturer was adding more to each slide. More interactive with students and emphasizes the main points of what the lecturer is saying. (Theme 4)

The tablet PC allowed students to understand the lecture notes in a more visual way. It was clearer to put concepts together. Diagrams and illustrations greatly improved my understanding. (Theme 5)

Allowed notes to be taken at the same rate - allowed for drawings to be annotated and gone through simply. (Theme 7) 

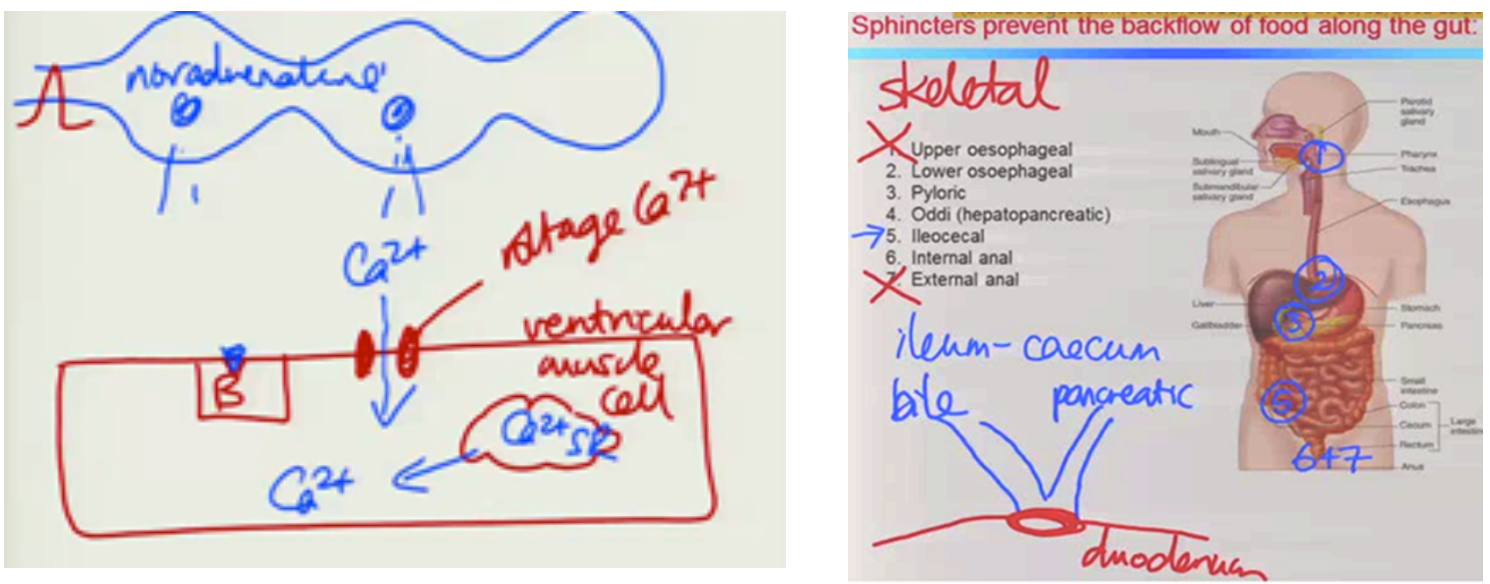

Figure 4. An example of a tablet PC diagram (left hand side) and an annotated slide (right hand side), taken as static images from the lecture recording

Regarding Theme 2 (Annotations on the digital video recording, "Echo", of the lecture), students commented on the usefulness of the recorded tablet PC lectures for review and revision purposes, especially because the annotations were visible, whereas laser pointer images do not appear on the lecture video recordings. Students particularly appreciated the ability to review the lecture with simultaneous playback of lecture slides, annotations and audio. The Echo video recording of lectures was introduced in semester one (for Physiology) and this would have contributed to the large number of written student comments about the tablet annotations on the lecture recordings for this subject.

Typical student comments about annotations on the digital video recordings of the lectures (Theme 2) included:

The tablet is good, especially when listening/watching at home. You can see where the lecturer is up to. Being able to see what the lecturer was pointing to after it has been said. This is difficult with a laser pointer if you are looking down taking notes.

When listening to the lectures online it was incredibly helpful to be able to see the lecturers' annotations on the lecture recoding. And it was good that the lecturer could post the post-lecture notes (with their annotations) online.

Students were asked to respond to the statement, "Briefly comment on how the tablet PC lectures could be improved in the future". These responses were categorised into seven main themes (see Table 3). Of these responses, $48 \%$ related to the lack of lecturer experience and proficiency with this technology (Theme 1). Students also commented about the poor quality of the handwriting and diagrams on the tablet PC and the excessive use of highlighting and circling of bullet points on the slides.

Typical student comments in response to the statement "Briefly comment on how the tablet PC lectures could be improved in the future":

- When lecturers highlight everything on the slide it gets a bit messy and confusing - the use of tablets through choice of key points would be better. (Themes 2 and 3 )

- Tell the lecturers to stop scribbling all over the page. It is pointless! Only use the tablet to write important notes and illustrate essential points. (Theme 2)

- Lecturers need to improve handwriting when writing on slides - sometimes what they wrote was impossible to read. (Theme 2)

- The handwriting was hard to read. And most lecturers just circled or underlined things which were already pretty obvious. (Theme 2)

- The handwriting was hard to read. And most lecturers just circled or underlined things which were already pretty obvious. (Theme 2)

- $\quad$ Sometimes there were too many highlights and colours. This was a distraction when notes were looked at afterwards and was a little confusing. (Theme 3) 
- I think that some of the lecturers need to work on how they use the tablet a little bit more - going through each slide and highlighting all of the content is not really an advantage or does not make the lecture content clearer. (Themes 1 and 3)

- Lecturers spent more time figuring out how to write stuff than on what they were actually trying to explain. (Theme 1)

Table 3

Main themes of the student responses to the question, "Briefly comment on how the tablet PC lectures could be improved in the future" for two biomedical subjects

\begin{tabular}{lcc}
\hline $\begin{array}{l}\text { Main themes of the student responses to, "Briefly } \\
\text { comment on how the tablet PC lectures could be } \\
\text { improved in the future". }\end{array}$ & $\begin{array}{c}\text { Physiology } \\
\text { (number of comments) }\end{array}$ & $\begin{array}{c}\text { Bioinformatics } \\
\text { (number of comments) }\end{array}$ \\
\hline $\begin{array}{l}\text { (1) Lecturers need more training and/or practise } \\
\text { with the tablet PC technology. }\end{array}$ & 7 \\
(2) Lecturers should provide neater writing. & 4 \\
(3) Lecturers should use less of the highlighting & \\
function. & 3 \\
(4) Lecturers should all provide lecture notes with \\
the tablet PC annotations and diagrams. \\
(5) Lecturers should use more diagrams and \\
drawings.
\end{tabular}

Note: Total number of comments: Physiology, $n=35$; Bioinformatics $n=34$.

\section{Lecturer experiences with the preparation and delivery of tablet PC lectures}

Lecturers who used tablet PCs to lecture in 2nd year biomedical science subjects (Physiology, Bioinformatics, Anatomy, Biochemistry, Microbiology and Genetics) in 2010 were surveyed to investigate if the transition from non-tablet PowerPoint lectures (with a laser pointer) to tablet PC lectures (with a digital pen) caused them to alter their lecture preparation, delivery, content or student lecture notes. Seven lecturers completed the survey. This was a response rate of $70 \%$ (10 of the 25,2 nd year BMS lecturers used a tablet PC for lecturing in 2010). Since these surveys were anonymous, it was not possible to determine if the lecturers were specifically teaching in Physiology or Bioinformatics.

Lecturers were asked to tick provided responses to, "Why did you choose to use the tablet PC for lecturing?" As shown in Table 4, all but one of the lecturers indicated that the support (a technician was provided during all of the tablet lectures) and training were crucial in their choice to use a tablet for lecturing. Other important factors included that the tablet provided opportunities for creating more pedagogically active lectures and for revising and reviewing existing lectures (see Table 4).

In the year prior to the study, all of the participating lecturers had used PowerPoint slide presentations with a laser pointer. Lecturers also attended a tablet PC training session before preparing their tablet lectures. When preparing the tablet PC lectures, six of the seven lecturers used existing PowerPoint lectures and one created new lectures (using Classroom Presenter). All of the lecturers used the digital inking function of the tablet PC. Six of the lecturers used Classroom Presenter software and one used PowerPoint. 
Table 4

Lecturer motivations for volunteering to use a tablet PC for lecturing

\begin{tabular}{lc}
\hline "Why did you choose to use the tablet PC for lecturing?" & $\begin{array}{c}\text { Number of lecturers } \\
(n=7)\end{array}$ \\
\hline Adequate support and training was provided & 6 \\
I thought it would make my lectures more interactive & 5 \\
It provided me with the opportunity to revise and review my current lectures & 5 \\
I wanted to use the new technology & 4 \\
I thought it might improve student attendance at my lectures & 3 \\
I liked the idea of using a digital pen instead of a laser pointer & 2 \\
Other reasons & 0 \\
\hline
\end{tabular}

The section of the survey about preparation and delivery of tablet PC lectures was answered by six lecturers; they all altered their lecture delivery or content for use with the tablet PC. They were specifically asked to reflect and comment on how their 2010 tablet lectures were different (or similar) to their equivalent PowerPoint lectures in 2009; all of the lecturers decreased the number of slides, three decreased the number of lecture learning objectives and main lecture concepts (three did not change these) and four replaced digital images with hand-drawn images. Lecturers were asked to estimate how long it took to prepare each tablet lecture, and their responses ranged from 0.5-10 hours. All of the lecturers provided the students with pre-lecture notes that were a PDF version of the slides. During the delivery of the lectures, all lecturers generated written text and diagrams, and used the highlighting function. Two of the lecturers also used the whiteboard function. Only two of the lecturers were unable to present all of their planned lecture content (and this was not due to technical problems).

The lecturers' responses to statements about the ease of preparation and delivery of their tablet lectures are shown in Figure 5. Five of seven lecturers agreed, one disagreed and one was neutral that the tablet lectures were easy to prepare, and to set up and deliver in the lecture theatre. Two of the seven lecturers did not feel confident about using a tablet for lecturing without technical support in the lecture theatre. This highlights that most of the lecturers experienced technical problems during the lecture; five lecturers reported technical problems that interfered with their tablet PC lecture presentations. However, all of the lecturers indicated that they would use a tablet PC for lecturing again if given the opportunity.

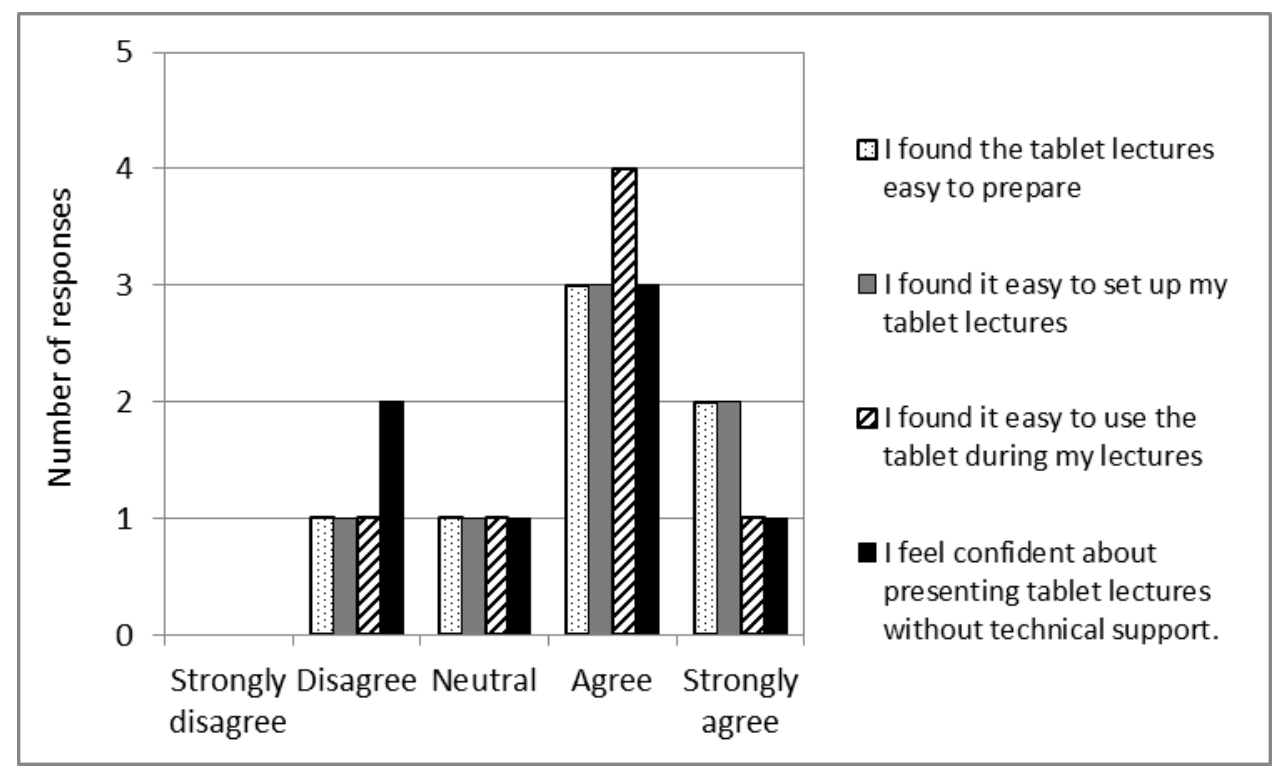

Figure 5. Lecturers' responses to statements about the preparation and delivery of their tablet PC lectures $(n=6)$ 
Typical lecturer comments included:

- The technical problems in the lecture theatres made using the tablet a hit or miss proposition so I couldn't always reap the benefits of my labour (i.e. the amount of time spent preparing the tablet lectures).

- The image projected on the screen was not the same as on the tablet, the pen software was unreliable, the tablet stopped working, the expanded screen didn't work in all lecture theatres and sometimes I had to go back to basic PowerPoint with a laser pointer (which was disheartening).

- I did not use the tablet to its full advantage. I only did what I was able to do. I could not manage to do the instructors notes.

- I could not go to the animations on the web easily...so I flipped between tablet/CP3 and the computer to do this.

- The screen on tablet needs to be larger - this would make writing during lectures easier and more legible.

Follow-up interviews with three of the original 2010 tablet PC lecturers, three years after the initial study, clarified that the tablet PC lectures slowed down the pace of their lecture delivery relative to their previous non-tablet lectures. This meant that over the years they had modified their lectures so that they included less content and contained fewer learning objectives. All three of these lecturers also reported that they had reduced the amount of text on their slides and replaced much of this with visual images (see lecturer comment below). They also indicated that their preparation of tablet PC lectures was now much quicker than in their initial year of tablet lecturing. One lecturer reported generating entire graphs and diagrams during the course of their lectures:

Using the tablet PC reduced the amount of text-based content that was provided to students as the "lecture slides" that they can download and bring to the lecture. I found with the revised tablet based lectures I tended to incorporate a lot more visual content, images, figures, annotations, drawing diagrams; and a lot of the content was 'added' during the lecture, rather than provided to students beforehand. All this does slow down the pace during lecture delivery - but as students are writing notes on the "slides" in the same way that you are, then the slower pace suits their note-taking.

When asked about technical issues with the tablet PC lectures, all three lecturers indicated that they no longer had technical issues with the tablet PC presentations and that the only technical issues they had encountered over the last few years resulted from technical issues not associated with the tablet PC (e.g. the digital projector in the lecture theatre failed).

\section{Discussion}

\section{Student perceptions and lecturer experiences of the tablet PC lectures}

Survey responses showed that the majority of students from both subjects felt that the tablet PC lectures enabled them to keep up with the pace of the lectures (83\% from Physiology, 75\% from Bioinformatics), found the lectures interesting (87\% from Physiology, 67\% from Bioinformatics) and thought that they enhanced their understanding of the lecture content (80\% from Physiology, $66 \%$ from Bioinformatics). Similarly, Grainger et al. (2011) reported that $75 \%$ of engineering students indicated good or very good perceptions of the digital inking on tablet PC lecture (with only 50\% for electronic whiteboards). Lectures with prepared images that cannot be altered in real-time can result in inflexible lectures that concentrate on content delivery (Clark, 2008). The flexible nature of the tablet PC lectures encouraged lecturers to use variety in their presentation, with real-time drawing, written comments, graphs and diagrams. These effects, as noted in the students' written comments, seemed to make the lectures more pedagogically interactive and encouraged student attentiveness and participation via note-taking. The 
digital inking on the tablet PC appeared to contribute to a slower lecture pace, as indicated by the student and lecturer feedback.

Students commented that the best aspects of the tablet PC lectures were the digital inking through written text, diagrams and drawings, together with the availability of digital recordings of the lectures (with the digital inking). They also indicated that they found the digital Echo video recordings of the tablet PC lectures particularly useful, especially for lecture revision. This was principally because the recording allowed the digital inking to be visible, whereas a laser pointer is not visible on these lecture recordings. Similarly, Yoon and Sneddon (2011) investigated student perceptions of undergraduate mathematical tablet PC lectures that were digitally video captured. They found that students commonly viewed the video recordings to review points they did not understand during the live lecture and to help them with test or exam revision. With tablet PC lecture recordings students can view the "evolution of written text on the slides" and visualise "deictic (pointing) gestures in the form of underlining and highlighting", allowing them to connect the visual images to the "[audio recordings of the] spoken deictics ['this', 'that', here']" (Yoon \& Sneddon, 2011, p.428); our students commented that they appreciated being able to watch the evolution of text, flow charts and diagrams on the Echo video recordings, but suggested that lecturers tended to overuse the highlighting function.

Student survey responses for the semester one Physiology subject were consistently higher than for the second semester Bioinformatics subject (with the same student cohort). This might reflect the fact that in Physiology all lecturers used a tablet PC, whereas in Bioinformatics the tablet PC was used by only one lecturer. There were also fewer lectures in Bioinformatics (24, as compared with 36 for Physiology).

As reported in previous studies investigating lecturer experiences of tablet PC lectures (Lim, 2011; Weitz et al., 2006), the majority of lecturers reported technical difficulties during lectures that interfered with the lecture presentation, despite the presence of technical staff in the lecture theatre. The follow up interviews with three of the lecturers found that in the subsequent years after the initial 2010 tablet PC lectures, they no longer had problems with the tablet PC technology.

\section{Limitations of the study}

The results of this study are limited by the small sample of lecturers who responded to the survey (7 of the 10 BMS tablet PC lecturers) and the limited number of questions $(n=3)$ on the student survey. The data is also the self-reported perceptions of lecturers and students. This study also selected students who were motivated to attend their lectures, because the survey was completed by students who attended the final lecture for each subject (and who took the time to complete the voluntary student survey). It is possible that this introduced selection bias; the views of students who did not attend the final lecture could have been enlightening. Most students who completed the survey agreed or strongly agreed with the statement, "When the lecturer used a tablet PC in class it made the lecture more interesting and engaging". We did not define for the students what we meant by an engaging lecture; we believe that most students would have interpreted this as involvement with (e.g., via note-taking) or interest in the lecture, since we also used the word "interesting" in this statement. Their written comments suggested that the tablet lectures helped them to take notes at the same time as the lecturer (activity to enhance engagement) and to understand the lecture through interpretation of visual annotations (cognitive engagement).

Learning outcomes (student performance) and lecture attendance were not investigated in this study; it is dangerous to assume that improvements in the student experience necessarily translate into improved learning outcomes (Clark, 2010). For future explorations of tablet PC lectures, the study design could be improved by: in-lecture overt observations; counting lecture attendance; following up the student survey with student focus groups and individual interviews to clarify and expand the main themes that had emerged from the surveys; ensuring that engagement is defined in surveys; specifically asking students about the lecture pace; and investigating student note-taking.

\section{Conclusions and future directions}

This study identified a number of benefits to both students and lecturers that resulted from the use of tablet PCs for large class biomedicine lectures. Relative to non-tablet lectures with prepared images and a 
laser pointer, feedback from the students suggested that they found the tablet lectures more interesting, at a more manageable pace and comprehensible. Lecturers that used the tablet PC reduced their lecture content and slowed down their lecturing pace. They also made use of the digital pen to annotate pictures and draw diagrams. Taken together, these effects could contribute to greater active participation by students during the tablet PC lectures, especially by promoting student note-taking during lectures. The tablet PC lectures therefore appear to support the signaling principle of Cognitive Load Theory and, via the real-time drawing of ad-hoc graphics, the modality principle (Carlson, et al., 2003; Ginns, 2005). Both of these effects may result in improved student learning and active involvement during their lectures.

However, both students and lecturers commented on aspects of the tablet PC implementation that could be improved. The most frequent comment by students related to better lecturer training and practise with the technology, even though all lecturers in this study were provided with formal training in the use of tablet PC and associated software prior to the start of their tablet lectures. This was the first time all of the lecturers had used tablet PCs in lectures, so it was not surprising that students mentioned a lack of experience. Lecturers commented on the significant amount of time that they spent on lecture preparation (up to 10 hours per lecture). As noted by Anderson et al. (2005), unless instructors plan ahead for digital inking (e.g. leaving adequate space, choosing appropriate colours, practising maintaining eye contact with the students when inking) the tablet technology will become a distraction rather than a teaching tool that enhances interaction and flexibility. This ability to plan ahead for tablet annotations is something that is also likely to improve with practise. Our follow-up interviews with lecturers three years after their initial tablet PC lectures found that they had significantly reduced lecture preparation time and that they were making more use of the digital inking features of the tablet, including generating complete diagrams during the lecture.

Leading on from the success of the pilot study of tablet PC lecturing in the School of Biomedical Sciences, the University established a "Tablets for Teachers" program across the whole University in 2012. In this program, lecturers can borrow a tablet PC for a semester and get advice and training on how to use a tablet PC and relevant software tools (primarily from pedagogical specialists, but with technical support from IT staff with tablet expertise). The costs of these pedagogical and IT staff were factored into the financing of this program. The University also plans to incorporate fixed tablet-style lecterns into all lecture theatres. In recent years some universities have been giving students and lecturers iPads, with all their learning materials, including digital textbooks. For example, the three major higher education institutions in the United Arab Emirates are providing iPads to all students (Hargis, Cavanaugh, Kamali, \& Soto, 2013); and some universities in Australia are providing them to cohorts of students (e.g. Henderson \& Pike, 2012). With the right apps, these devices could support digital inking by teachers and students, while being more portable; future research will hopefully evaluate the efficacy of inking with new devices. But in an era of educational belt tightening, these programs are not without their critics (Palmer \& Creagh, 2012), and will be expected to demonstrate their pedagogical- and cost-effectiveness.

\section{References}

Anderson, R., Anderson, R., McDowell, L., \& Simon, B. (2005). Use of classroom presenter in engineering courses. Proceedings of the $35^{\text {th }}$ ASEE/IEEE Frontiers in Education Conference, Indianapolis, USARetrieved from http://fie-conference.org/fie2005/.

Baron, P., \& Corbin, L. (2012). Student engagement: rhetoric and reality. Higher Education Research \& Development, 31(6), 759-772. doi: 10.1080/07294360.2012.655711

Carlson, R., Chandler, P., \& Sweller, J. (2003). Learning and understanding science instructional material. Journal of Educational Psychology, 95, 629-640.

Clark, J. (2008). PowerPoint and pedagogy: Maintaining student interest in university lectures. College Teaching, 56(1), 39-45.

Clark, R. C. (2010). Evidence-based training methods: A guide for training professionals. Alexandria, VA: American Society for Training \& Development. 
Clark, R., Nguyen, F., \& Sweller, J. (2006). Efficiency in learning: Evidence-based guidelines to manage cognitive load. San Francisco, CA: Pfeiffer.

Cox, J. R. (2011). Enhancing student interactions with the instructor and content using pen-based technology, YouTube videos, and virtual conferencing. Biochemistry and Molecular Biology Education, 39(1), 4-9.

Dawson, P. (2010). Networked interactive whiteboards: Rationale, affordances and new pedagogies for regional Australian higher education. Australasian Journal of Educational Technology, 26(4), 523533.

Derting, T. R., \& Cox, J. R. (2008). Using a tablet PC to enhance student engagement and learning in an introductory organic chemistry course. Journal of Chemical Education, 85(12), 1638-1643.

Felder, R. M., \& Silverman, L. K. (1988). Learning and teaching styles in engineering education. Engineering Education, 78(7), 674-681.

Ginns, P. (2005). Meta-analysis of the modality effect. Learning and Instruction, 15(4), 313-331.

Grainger, S., Kestell, C., \& Willis, C. (2011). Staff and student perceptions of the effective use of contemporary lecture theatre technology. Proceedings of the 2011 AAEE Conference, Fremantle, Australia, 607-611. Retrieved from http://www.aaee.com.au/conferences/2011/papers/AAEE2011/ PDF/INDEXSCR.PDF.

Hargis, J., Cavanaugh, C., Kamali, T., \& Soto, M. (2013). A federal higher education iPad mobile learning initiative: Triangulation of data to determines early effectiveness. Innovative Higher Education, 39(1), 1-13.

Henderson, U., \& Pike, S. M. (2012). The iPad guarantee: information literacy, the library and a reinvigorated undergraduate science program. VALA Conference Proceedings, Melbourne, Australia. Retrieved from http://www.vala.org.au/vala2012-proceedings/vala2012-session-4-henderson.

Higgins, S., Beauchamp, G., \& Miller, D. (2007). Reviewing the literature on interactive whiteboards. Learning, Media and Technology, 32(3), 213-225.

Jakee, K. (2011). Overhauling technical handouts for active student participation: a model for improving lecture efficiency and increasing attendance. International Journal of Teaching and Learning in Higher Education, 23(1), 98-108.

Johnson, A. E. (2008). Digital ink: In-class annotation of powerpoint lectures. Journal of Chemical Education, 85(5), 655-657.

Kam, M., Wang, J., Iles, A., Chiu, J., Glaser, D., Tarshish, O., \& Canny, J. (2005). Livenotes: A system for cooperative and augmented note-taking in lectures. Proceedings of the SIGCHI Conference on Human Factors in Computing Systems, Portland, USA, 531-539. Retrieved from http://people.cs.pitt.edu/ jingtaow/research/livenotes-chi2005.pdf.

Kiewa, K. A. (1985). Investigating notetaking and review: A depth of processing alternative. Educational Psychologist, 20(1), 23-32.

Krathwohl, D. R. (2002). A revision of bloom's taxonomy: An overview. Theory into Practice, 41(4), 212-218.

Lim, K. Y. (2011). What does the Tablet PC mean to you? A phenomenological research. Innovations in Education and Teaching, 48(3), 323-333. 
Loch, B., Galligan, L., Hobohm, C., \& McDonald, C. (2011). Learner-centred mathematics and statistics education using netbook tablet PCs. International Journal of Mathematical Education in Science and Technology, 42(7), 939-949.

Lumkes, J. H. (2010). Survey of three different methods of delivering engineering content in lectures. Journal of Educational Technology Systems, 38(3), 249-366.

Mock, K. (2004). Teaching with Tablet PC's. Journal of Computing Sciences in Colleges, 20, 17-27.

Palmer, C., \& Creagh, S. (2012, December 20). Free 'trinkets' while courses cut: union condemns UWS iPads plan, The Conversation. Retrieved from https://theconversation.edu.au/moocs-and-exercisebikes-more-in-common-than-youd-think-9726.

Peverley, S. T., Ramaswamy, V., Brown, C., Sumowksi, J., Alidoost, M. \& Garner, J. (2007). What predicts skill in lecture note taking? Journal of Educational Psychology, 99(1), 167-180.

Selwyn, N. (2010). Looking beyond learning: notes towards the critical study of educational technology. Journal of Computer Assisted Learning, 26(1), 65-73.

Thomas, D. R. (2006). A general inductive approach for analyzing qualitative evaluation data. American Journal of Evaluation, 27(2), 237-246.

Tilbrook, A. (2010). Impact of tablet-based teaching on student learning outcomes and engagement. The Australasian Tablets in Education Conference, Melbourne, Australia. Retrieved from http://www.monash.edu.au/eeducation/research/atiec.html.

Tintarev, K., \& Rydén, J. (2010). Teaching with digital inkboards. Retrieved from http://www2.math.uu.se/ tintarev/ink/Article-uu.pdf.

Titsworth, B. S., \& Kiewa, K.A. (2004). Spoken organizational lecture cues and student notetaking as facilitators of student learning. Contemporary Educational Psychology, 29, 447-461.

Trowler, V. (2010). Student engagement literature review. York: The Higher Education Academy.

Van Oosteveen, R., \& Muirhead, W. (2007). Faculty use of tablet computers at the University of Ontario Institute of Technology. Canadian Journal of Learning and Technology, 33(1).

Weitz, R., Wachsmuth, B., \& Mirliss, D. (2006). The Tablet PC for faculty: A pilot project. Educational Technology \& Society, 9(2), 68-83.

Yoon, C., \& Sneddon, J. (2011). Student perceptions of effective use of tablet PC recorded lectures in undergraduate mathematics courses. International Journal of Mathematical Education in Science and Technology, 42(4), 425-445.

Corresponding author: Julie Choate, Julia.Choate@monash.edu.

Australasian Journal of Educational Technology (C) 2014.

Please cite as: Choate, J., Kotsanas, G. \& Dawson, P. (2014). Exploring tablet PC lectures: Lecturer experiences and student perceptions in biomedicine. Australasian Journal of Educational Technology, $30(2), 167-183$. 